\title{
AUDIT TATA KELOLA TEKNOLOGI INFORMASI UNTUK INTEGRITAS DATA MENGGUNAKAN FRAMEWORK COBIT 5 PADA PT KERETA API INDONESIA (PERSERO) DIVRE IV TNK
}

\author{
Rachmad Nugroho' ${ }^{1)}$, Ryan Randy Suryono ${ }^{2)}$, Dedi Darwis ${ }^{3)}$ \\ 1), 2) Sistem Informasi, STMIK Teknokrat \\ ${ }^{3)}$ Manajemen Informatika, AMIK Teknokrat \\ Jl. H.ZA Pagaralam, No 9-11, Labuhanratu,Bandarlampung \\ Email : rachmadnugrohoooo@gmail.com ${ }^{1)}$,ryan.dataku@gmail.com ${ }^{2}$ darwisdedi@teknokrat.ac.id ${ }^{3)}$
}

\begin{abstract}
Abstrak
PT Kereta Api Indonesia (Persero) Divre IV Tanjungkarang merupakan salah satu badan usaha milik negara yang bergerak dalam bidang jasa transportasi yang telah memanfaatkan teknologi informasi yaitu penggunaan system Trainplan. Namun dalam penerepan sistem Trainplan terdapat beberapa kendala yaitu salah satunya integritas data yang terjadi kurang baik sehingga dalam mendukung meraih tujuan perusahaan kurang maksimal.
\end{abstract}

Untuk memastikan keakuratan, aksesibilitasi dan kualitas tinggi dari sebuah data, maka harus dilakukan audit sistem informasi. Audit sistem informasi dilakukan untuk meningkatkan integritas data pada PT Kereta Api Indonesia (Persero) Divre IV Tanjungkarang. Pengumpulan data dilakukan dengan cara menyebarkan kuesioner, wawancara, dokumentasi dan observasi secara langsung.

Hasil pengumpulan data digunakan untuk mengetahui kelemahan-kelemahan sistem pada PT Kereta Api Indonesia (Persero) Divre IV Tanjungkarang. Audit sistem informasi ini menggunakan framework COBIT 5. Domain yang digunakan pada penelitian ini adalah Evaluate Direct and Monitor (EDM), Align Plan and Organise (APO), Build Acquire and Implement (BAI), Deliver Service and Support (DSS), dan Monitor Evaluate and Assure (MEA) yang bertujuan mengetahui sejauh mana PT Kereta Api Indonesia (Persero) Divre IV Tanjungkarang telah menerapkan integritas data dan informasi.

Kata kunci: COBIT 5, Audit Sistem Informasi, Tata Kelola, Trainplan, Integritas Data

\section{A. Latar Belakang \\ PT Kereta Api Indonesia (Persero) Divre IV} Tanjungkarang merupakan salah satu Badan Usaha Milik Negara yang menggunakan teknologi informasi (TI) diseluruh Divisi yang ada. Saat ini Teknoogi informasi tidak hanya digunakan sebagai faktor pendukung dalam perusahaan, tetapi juga sebgai bagian dari strategi proses bisnis perusahaan. Agar teknologi informasi dapat digunakan secara optimal, diperlukan suatu tata kelola teknologi informasi [1]. Tata kelola teknologi informasi adalah bagian dari tata kelola yang menitikberatkan pada sistem dan teknologi informasi serta manajemen kinerja dan risikonya. COBIT (Control Objectives for Information and Related Technology) adalah salah satu standar pengukuran yang digunakan dalam tata kelola teknologi informasi. Standar COBIT mengukur kinerja tata kelola teknologi informasi yang sesuai dengan tujuan bisnis perusahaan. Layanan teknologi informasi yang tepat waktu, akurat dan relevan dengan kebutuhan user merupakan hal yang paling penting diperhatikan dalam mendukung kelancaran pelaksanaan aktivitas suatu organasasi termasuk perusahaan yang bergerak di bidang jasa transportasi ini. Tujuan dapat dihasilkan apabila didukung dengan sistem tata kelola teknologi informasi yang baik sejak tahap perencanaan, implementasi dan evaluasi [2]. Framework COBIT terdapat dua versi yaitu COBIT 4.1 dan Cobit 5. PT Kereta Api Indonesia (Persero) Divre IV Tanjungkarang dalam Peraturan Dinas No. 19 Jilid I tentang Urusan Perjalanan kereta Api dan Urusan Langsir, Pasal 17 Ayat 1 menetapkan perjalanan Kereta Api Luar Biasa (KLB) harus dilakukan dengan Maklumat Perjalanan Kereta Api (MALKA) dan Warta Maklumat (WAM). Berdasarkan dasar tersebut PT Kereta Api Indonesia (Persero) Divre IV Tanjungkarang setiap ada perjalanan Kereta Api Luar Biasa (KLB) harus memiliki surat perintas perjalanan atau dalam istilah perkeretapaian disebut Warta Maklumat (WAM), yang mana pembuatan Warta Maklumat (WAM) itu sendiri sudah menggunakan teknologi infomasi Trainplan untuk mempermudah dalam pebuatan dan pendistribusian informasi ke stasiun stasiun dan upt crew yang terkait perjalanan Kereta Api Luar Biasa (KLB). menyadari pentingnya kegiatan pengelolaan dan evaluasi tata kelola teknologi informasi yang telah diterapkan karena bermanfaat untuk mengetahui bagaimana kinerja sistem yang berjalan saat ini terutama untuk integritas data untuk mengatasi terjadinya tidak dapat informasi, tidak akurat perjalanan Kereta Api Luar Biasa (KLB). Kerangka COBIT 5 membagi proses teknologi informasi menjadi 5 domain, yaitu EDM (Evaluate, Direct and Monitor), APO (Align, Plan and Organise), BAI (Build, Acquire and Implement), DSS (Deliver, Service, and Support), MEA (Monitor, Evaluate and Assess) dengan keseluruhan 37 proses yang ada didalamnya. 
(ISACA, 2012). COBIT 5 dipilih karena memiliki cakupan yang luas untuk proses pengelolaan teknologi informasi, kedetilan proses dan aktivitasnya.

Rumusan Masalah yang dibuat adalah bagaimana menganalisis tata kelola untukintegritas data pada sistem Trainplan dengan menggunakan framework COBIT 5 dengan Domain proses EDM03, APO01, APO02, BAI01, BAI02, BAI04, DSS01, MEA01 pada PT Kereta Api Indonesia (Persero) Dvire IV Tanjungkarang dan bagaimana hasil evaluasi analisis sistem tata kelola kemanan informasi menggunakan framework COBIT 5 dengan Domain EDM (Evaluate, Direct and Monitor), APO (Align, Plan and Organise), BAI (Build, Acquire and Implement), DSS (Deliver, Service, and Support), MEA (Monitor, Evaluate and Assess).

Tujuan penelitian ini adalah Menagalisis tata kelola untuk integritas data pada sistem Trainplan dengan menggunkan framework COBIT 5 dengan Domain proses EDM03, APO01, APO02, BAI01, BAI02, BAI04, DSS01, MEA01 pada PT Kereta Api Indonesia (Persero) Divre IV Tanjungkarang.Untuk mengetahui hasil evaluasi analisis sistem tata kelola integritas data menggunakan framewok COBIT 5 dengan Domain EDM (Evaluate, Direct and Monitor), APO Align, Plan and Organise), BAI (Build, Acquire and Implement), DSS (Deliver, Service, and Support), MEA (Monitor, Evaluate and Assess) pada PT Kereta Api Indonesia (Persero) Divre IV Tanjungkarang.

\section{B. Landasan Teori}

\section{Tinjauan Pustaka}

Tinjauan Pustaka pada Penelitian ini di referensi dari beberapa penelitian sebelumnya yaitu:

a) Audit Sistem Informasi Menggunakan Framework COBIT 5 Sebagai Upaya Peningkatan Keamanan Data Pada SMKK BPK Penabur Bandar Lampung. Pada penelitian ini objek yang dituju Evaluasi Tata Kelola Teknologi Informasi pada SMK BPK Penabur Bandar Lampungkesimpulan yang di dapat adalah SMKK BPK Penabur Bandarlampung telah menerapkan proses pengamanan data dan informasi pada rata-rata level Repeatable but Intuitive. Hasil pengolahan kuesioner mendapati nilai rata-rata untuk domain MEA, APO, BAI, DSS, dan MEA adalah 2,3 dari rentang nilai 0 sampai 5. Artinya SMKK BPK Penabur Bandarlampung telah melakukan proses pengamanan namun belum baku atau belum mengikuti standar yang [1].

b) Audit Tata Kelola Kemanan Informasi Pada Kantor Wilayah Kementerian Agama Provinsi Lampung Menggunakan Framework COBIT 5. Metode yang digunakan dalam penelitian ini adalah Framework COBIT 5 sebagai metode untuk evaluasi maturitylevel dalam tata kelola kemanan informasi pada kantor wilayah Kementerian Agama Provinsi Lampung. Objek penelitian dalam tulisan ini adalah Evaluasi MaturityLevel Dalam Tata Kelola kemanan informasi pada kantor wilayah
Kementerian Agama Provinsi Lampung. Hasil evaluasi menemukan variasi antara kedelapan proses domain yang digunakan untuk menganalisis tata kelola keamanan informasi, diamana pada proses EDM03, APO01, APO07, APO12, BAI06, DSS01, DSS02, DSS05, dan MEA02 dikategorikan kedalam Defined Process kemudian untuk proses domain APO01, DSS03, dan MEA01 dikategorikan kedalam Managed and Measureabel[2].

c) Evaluasi Tingkat Kematangan Tata Kelola Teknologi Informasi STAIN Kediri Menggunakan Framework COBIT 5.Objek penelitian dalam tulisan ini adalah Evaluasi Tingkat Kematangan Tata Kelola Teknologi Informasi STAIN Kediri. Berdasarkan analisis temuan audit menggunakan COBIT 5, untuk keenam proses IT relatedgoals sebelumnya, staf operator IT dan sistem yang digunakan di STAIN Kediri sebagian besar masih dalam tahap reaktif $[8]$.

d) Evaluasi Tingkat Kematangan Teknologi Informasi Dengan Menggunakan Model Maturity Level Cobit 4.1. Permasalahan yang dikaji dalam penelitian ini adalah kinerja IT belum maksimal, hal ini disebabkan karena pergantian kepemimpinan yang sering terjadi. Selain itu kurangnya pengetahuan untuk menilai kualitas software yang digunakan sehingga tidak diketahui apakah aplikasi yang digunakan efektif dan efisien untuk proses bisnis yang ada. Teridentifikasi proses pada domain Plan and Organise (PO) terutama mengelola kualitas PO8 berpengaruh dalam pengelolaan IT pada PT BRI Cabang Bangkinang. Dari hasil pengukuran maturity model, diketahui bahwa tingkat kematangan IT domain PO8 berada antara tingkat repeatable dan defined dengan skor rata-rata 2.9 [5].

e) Audit Tata Kelola Teknologi Informasi Untuk mengontrol Manajemen Kualitas Menggunakan Cobit 4.1.Permasalahan yang dikaji dalam penelitian ini adalah masih rendahnya tingkat kepedulian manajenen terhadap penggunaan TI di PT Nikkatsu Electric Works khususnya dalam mengontrol manajemen kualitas dan belum diketahuinya tingkat kematangan di perusahaan pada proses pengawasan dan evaluasi kinerja TI. Kesimpulan pada penelitian ini adalah Tingkat kepedulian manajemen (management awareness) pada saat ini ada di angka 1,78 artinya tingkat kepedulian manajemen terhadap TI masih rendah. Sehingga secara tidak langsung dapat mempengaruhi tingakt kematangan pada PT Nikkatsu Electric Works. [6]. 


\section{Definisi Audit}

Audit pada dasarnya adalah proses sistematis dan obyektif dalam memperoleh dan mengevaluasi buktibukti tindakan ekonomi, guna memberikan asersi / pernyataan dan menilai seberapa jauh tindakan ekonomi sudah sesuai dengan kriteria yang berlaku dan mengkomunikasikan hasilnya kepada pihak terkait [9].

\section{Jenis-Jenis Audit:}

1. Financial Audit, memeriksa keterdalaman dan integritas dari transaksi-transaksi keuangan, catatan akuntansi dan laporan keuangan.

2. Internal Control Audit, memeriksa kebijakan prosedur pengendalian internal serta efektifitas dalam pengamanan asset, audit tersebut biasanya mengevaluasi input dan output sistem, pengendalian pemrosesan, rencana backup dan pemulihan keamanan sistem serta fasilitas sistem.

3. Operational Audit, berkaitan dengan penggunaan secara ekonomis dan efisien atas sumber daya pencapaian tujuan serta sasaran yang diterapkan.

4. Compiance Audit, menentukan apakah entitas mematuhi hokum, peraturan, kebijakan, dan prosedur yang berlaku. Audit ini sering menghasilkan rekomendasi untuk meningkatkan proses dan pengendalian yang digunakan untuk memastikan kepatuhan terhadap regulasi.

5. Investigative Audit, menguji kejadian-kejadian dari penipuan yang mungkin terjadi, penggunaan asset yang tidak tepat, pemborosan dan penyalahgunaan atau aktivitas tata kelola yang buruk.[7].

\section{Tujuan Audit Sistem Informasi}

Tujuan audit sistem informasi adalah:"untuk memeriksa dan mengevakuasi pengendalian internal yang melindungi sistem". Ketika melakukan sebuah audit sistem informasi para auditor seharusnya memastikan bahwah enam tujuan berikut telah tercapai yaitu [7] :

1. Ketentutan keamanan untuk melindungi peralatan komputer, program, komunikasi dan data-data dari akses, modifikasi, atau penghancuan yang tidak di otorisasi.

2. Pengembangan dan akuisisi program dilakukan sesuai dengan otorisasi umum dan spesifikasi manajemen.

3. Modifikasi program mendapatkan otorisasi dan perssetujuan manajemen.

4. Pemrosesan transaksi, file, laporan, scatatan, dan catatan komputer lain nya tepat dan lengkap.

5. Data sumber yang tidak tepat atau tidak diotorisasi dengan benar diidentifikasi dan ditangani berdasarkan kebijakan manajerial yang telah ditentukan.

6. File-file data komputer tepat, lengkap, dan rahasia.

\section{Framework COBIT 5}

Framework COBIT (Control Objectives For Information and Related Technology) 5 merupakan generasi terbaru dari panduan ISACA yang dibuat berdasarkan pengalaman penggunaan COBIT selama lebih dari 15 tahun oleh banyak perusahaan dan penggunaan dari bidang bisnis, komunitas, teknologi informasi, risiko, asuransi, dan keamanan. Framework COBIT 5 mendefinisikan dan menjelaskan secara rinci sejumlah tata kelola dan manajemen proses. Framework COBIT 5 menyediakan kerangka kerja yang komprehensif yang membantu perusahaan dalam mencapai tujuan mereka untuk tata kelola dan manajemen aset informasi perusahaan dan teknologi. Secara sederhana, membantu perusahaan menciptakan nilai yang optimal dari TIdengan menjaga keseimbangan antara mewujudkan manfaat dan mengoptimalkan tingkat resiko dan penggunaan sumber daya. Framework COBIT 5 menggunakan praktik tata kelola dan manajemen untuk menjelaskan tindakan praktik yang baik untuk efek tata kelola dan manajemen teknologi informasi perusahaan.Framework COBIT 5 terdiri dari 5 domain, yaitu EDM, APO, BAI, DSS, dan MEA(ISACA, 2012) [4].

\section{Prinsip Dasar COBIT 5}

COBIT 5 (Control Objectivies Information and Related Technology) secara umum memiliki 5 prinsip dasar. [3]

Pada gambar 1 kita dapat melihat 5 prisip COBIT 5 sebagai berikut:

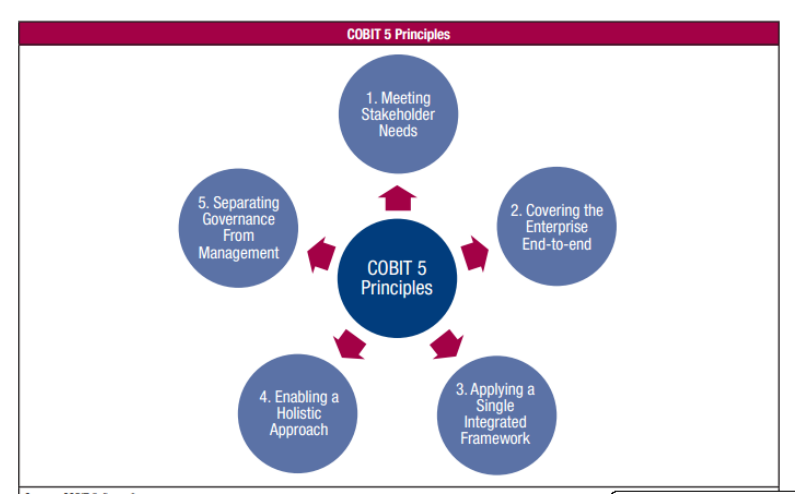

Gambar 1. Prinsip Dasar COBIT 5 


\section{Pembahasan}

\section{A. Tahapan Penelitian}

Berikut tahapan penelitian yang digunakan, dapat dilihat pada gambar 2 berikut ini:

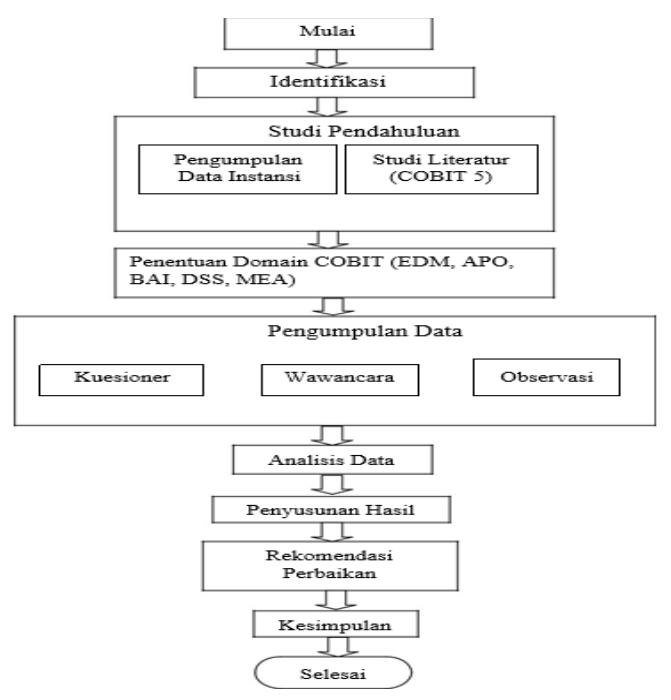

Gambar 2. Tahapan Penelitian

\section{B. Metode Pengumpulan Data}

1. Pengamatan

Metode ini dilakukan dengan mengumpulkan data yaitu dengan cara melakukan pengamatan secara langsung pada saat aplikasi Trainplan sedang digunakan, sehingga peneliti dapat mengetahui sistem yang sedang berjalan.

2. Wawancara

Metode ini dilakukan dengan cara mengajukan pertanyaan-pertanyaan secara langsung dengan Operator dan orang-orang yang terkait dalam penggunaan aplikasi Trainplan pada PT Kereta Api Indonesia (Persero) Divre IV Tanjungkarang, agar mendapatkan data yang berguna dalam penelitian yang dilakukan.

\section{Kuesioner}

Metode ini dilakukan dengan cara mengajukan pertanyaan tertulis yang akan diberikan ke karyawan dan orang-orang yang terkait dalam penggunaan Trainplan pada PT Kereta Api Indonesia (Persero) Divre IV Tanjungkarang, kemudian kuesioner digunakan untuk proses penelitian.

\section{Analisis Data}

1. Analisis Tingkat Kematangan (Maturity Level)

Dari hasil jawaban kuisioner tingkat kematangan,akan tersedia jawaban dengan nilai 0-5. Selanjutnya akan diambil rata-rata dari bobot jawaban setiap kegiatan proses audit tata kelola teknologi informasi untuk integritas data aplikasi Trainplan pada PT Kereta Api Indonesia (Persero) Divre IV Tanjungkarang dari setiap responden untuk mengetahui tingkat kematangan.
2. Analisis Kesenjangan $(G A P)$

Setelah diketahui keadaan aktual mengenai tingkat kematangan maka tahap selanjutnya adalah menganalisis kesenjangan. Analisis kesenjangan ini dilakukan untuk mengidentifikasi kegiatan apa saja yang perlu dilakukan oleh pihak manajemen.

\section{Hasil Identifikasi Enterprise Goals}

Pada tahap ini peneliti mengelompokkan enterprise goals dari PT Kereta Api Indonesia (Persero) Divre IV Tanjungkarang, dengan enterprise goals yang ada pada COBIT 5 dengan cara melihat tujuan penelitian yaitu meningkatkan integritas data maka peneliti mengkategorikan tujuan tersebut kedalam tujuan perusahaan (enterprise goals) yang terdapat pada COBIT 5 pada bagian Operasional And Staff Productivity. Enterprise goals dari PT Kereta Api Indonesia (Persero) termasuk dalam kategori Operasional And Staff Productivity karena PT Kereta Api Indonesia (Persero) Divre IV Tanjungkarang mengharapkan peningkatan integritas data pada system Trainplan.

\section{E. Hasil Identifikasi IT Related Goals}

Pada tahap ini peneliti melakukan pemilihan IT Related Goals, berdasarkan perbandingan matrik dari enterprise goals. Ada dua IT Related Goals yang memiliki hubungan yang bersifat "Primer" dengan Operasional And Staff Productivity yaitu Enablement and support of business process by integrating applications and technology into business process And Availability of reliable and usefull information for decision making.

\section{F. Identifikasi Domain COBIT 5}

Pada tahap ini, menetapkan Domain COBIT 5 yang sesuai dengan IT Related Goals yang telah disesuaikan dengan studi kasus pada PT Kereta Api Indonesia (Persero) Divre IV Tanjungkarang. Domain yang akan digunakan untuk proses audit dapat dilihat pada tabel 1 berikut ini :

Tabel 1. Domain COBIT 5

\begin{tabular}{|c|}
\hline Domain COBIT 5 \\
\hline EDM, APO, BAI, DSS, MEA \\
\hline
\end{tabular}

\section{G. Identifikasi Proses COBIT 5}

Pada tahap ini, menetapkan Proses COBIT 5 berdasarkan Domain COBIT 5 yang disesuaikan dengan studi kasus pada PT Kereta Api Indonesia (Persero) Divre IV Tanjungkarang. Proses yang akan digunakan untuk proses audit dapat dilihat pada tabel 2 berikut ini : 
Tabel 2. Proses Domain COBIT 5

\section{Proses COBIT 5}

EDM03, APO01, APO02,BAI01, BAI02, BAI03, DSS01, MEA01

\section{H. Identifikasi Control dan Indikator COBIT 5}

Pada tahap ini, menetapkan Control Activity COBIT 5 berdasarkan proses Domain COBIT 5 yang telah di pilih kemudian Object Control Activity akan disesuaikan dengan studi kasus pada PT Kereta Api Indonesia (Persero) Divre IV Tanjungkarang . Object Control Activity yang digunakan untuk proses audit dapat dilihat pada tabel 3 berikut ini :

Tabel 3. Object Control Activity COBIT 5

\begin{tabular}{|c|c|}
\hline No & Object Control Activity \\
\hline $\mathbf{1}$ & EDM03.01, EDM03.03 \\
\hline $\mathbf{2}$ & APO01.02, APO01.03, APO01.04, APO01.05 \\
\hline $\mathbf{3}$ & APO02.01, APO02.03 \\
\hline $\mathbf{4}$ & BAI01.02, BAI01.05, BAI01.06 \\
\hline $\mathbf{5}$ & BAI02.01, BAI02.02 \\
\hline $\mathbf{6}$ & BAI03.01, BAI03.03, BAI03.05 \\
\hline $\mathbf{7}$ & DSS01.01, DSS01.03, DSS01.05 \\
\hline $\mathbf{8}$ & MEA01.01, MEA01.02, MEA01.03, \\
& MEA01.04, MEA01.05 \\
\hline \multicolumn{2}{|c}{ Jumlah Butir Kuisioner 50 } \\
\hline
\end{tabular}

\section{Ringkasan Tingkat Kematangan}

Rata-rata hasil perhitungan dari proses COBIT 5 dijabarkan pada tabel 4 berikut ini :

Tabel 4. Rata-rata Tingkat Kematangan

\begin{tabular}{|l|l|l|l|}
\hline No & Proses & Keterangan & Nilai \\
\hline 1 & EDM03 & Memastikan Optimasi Risiko & 3.57 \\
\hline 2 & APO01 & $\begin{array}{l}\text { Mengelola Kerangka } \\
\text { Manajemen TI }\end{array}$ & 3.71 \\
\hline 3 & APO02 & Mengelola Strategi & 3.65 \\
\hline 4 & BAI01 & $\begin{array}{l}\text { Mengelola Program dan } \\
\text { Proyek }\end{array}$ & 3.75 \\
\hline 5 & BAI02 & $\begin{array}{l}\text { Mengelola Definisi } \\
\text { Kebutuhan }\end{array}$ & 3.63 \\
\hline 6 & BAI03 & $\begin{array}{l}\text { Mengelola Solusi, } \\
\text { Identifikasi dan Membangun }\end{array}$ & 3.67 \\
\hline 7 & DSS01 & Mengelola Operasi & 3.77 \\
\hline 8 & MEA01 & $\begin{array}{l}\text { Memonitor, Mengevaluasi, } \\
\text { Kenilai Kinerja dan } \\
\text { Kesesuaian }\end{array}$ & 3.71 \\
\hline & \multicolumn{2}{|l|}{ Nilai Rata-rata } & 3.68 \\
\hline
\end{tabular}

\section{J. Nilai Kesenjangan Kematangan (GAP)}

Berdasarkan nilai yang diketahui dari tingkat kematangan tata kelola yaitu sebesar 3,68 akan dilakukan analisis kesenjangan terhadap tingkat kematangan yang diharapkan yaitu sebesar 4. Hasil Analisa ini diharapkan dapat memberikan kemudahan untuk meningkatkan integritas data sesuai dengan yang diharapkan. Alasan nilai yang ditargetkan 4 adalah melihat ketersediaan dan kesiapan kantor dalam bidang integritas data sistem informasi terkait sistem Trainplan. Untuk melihat nilai kesenjangan dapat di lihat pada tabel 5 sebagai berikut :

Tabel 5. Analisis Kesenjangan (GAP)

\begin{tabular}{|c|c|c|c|c|}
\hline \multirow{2}{*}{ No } & \multirow{2}{*}{ Proses } & \multicolumn{3}{|c|}{ Tingkat Kematangan } \\
\cline { 3 - 5 } & & $\begin{array}{c}\text { Saat } \\
\text { ini }\end{array}$ & $\begin{array}{c}\text { Diharap } \\
\text { kan }\end{array}$ & GAP \\
\hline 1 & EDM03 & 3.57 & 4.00 & 0.43 \\
\hline 2 & APO01 & 3.71 & 4.00 & 0.29 \\
\hline 3 & APO02 & 3.65 & 4.00 & 0.35 \\
\hline 4 & BAI01 & 3.75 & 4.00 & 0.25 \\
\hline 5 & BAI02 & 3.63 & 4.00 & 0.38 \\
\hline 6 & BAI03 & 3.67 & 4.00 & 0.33 \\
\hline 7 & DSS01 & 3.77 & 4.00 & 0.23 \\
\hline 8 & MEA01 & 3.71 & 4.00 & 0.30 \\
\hline & \multicolumn{5}{|c|}{ Nilai Rata-rata } & 0.32 \\
\hline
\end{tabular}

\section{Kesimpulan}

Berikut ini merupakan simpulan dari hasil penelitian.

1. Menganalisis hasil penyebaran kuesioner dengan menghasilkan nilai rata-rata yaitu 3,68 dari nilai rentang nilai 0 sampai 5 pada domain EDM03, APO01, APO02, BAO01, BAO02, BAO03, DSS01 dan MEA01. Artinya PT Kereta Api Indonesia (Persero) Divre IV Tanjungkarang sudah melakukan proses integritas data dengan baku akan tetapi belum mencapai titik optimized dalam meningkatkan tata kelola integritas data.

2. Hasil evaluasi menemukan variasi antara kedelapan proses domain yang digunakan untuk menganalisis tata kelola integritas data, diamana nilai pada proses:

a. EDM03 nilai 3,57 dengan kondisi managed and measureabel

b. APO01 nilai 3,71 dengan kondisi managed and measureabel

c. APO02 nilai 3,65 dengan kondisi managed and measureabel

d. BAO01 nilai 3,75 dengan kondisi managed and measureabel 
e. BAO02 nilai 3,63 dengan kondisi managed and measureabel

f. BAO03 nilai 3,67 dengan kondisi managed and measureabel

g. DSS01 nilai 3,77 dengan kondisi managed and measureabel

h. MEA01 nilai 3,71 dengan kondisi managed and measureabel

Dengan nilai rata adalah 3,68 dikategorikan kedalam managed and measureabel.

Berdasarkan penelitian yang telah dilakukan peneliti merekomendasikan saran yang nantinya dapat digunakan oleh PT Kereta Api Indonesia (Persero) Divre IV Tanjungkarang untuk meningkatkan tata kelola integritas data sebagai landasan bagi penelitian selanjutnya.

1. Menggunakan sotware audit seperti GAS (Generalized Audit Software), ACL (Audit Command Language), Utility Program untuk menganalisis dan menguji data pada sebuah sistem.

2. Melakukan audit untuk tata kelola teknologi informasi secara keseluruhan pada PT Kereta Api Indonesia (Persero) Divre IV Tanjungkarang dengan menambahkan domain serta aktivitas yang sesuai dengan standar IT Goals dan kebutuhan organisasi.

\section{Daftar Pustaka}

[1] Darwis, Dedi., Abilianto, Dipo., 2016. Audit Sistem Informasi Menggunakan Framework COBIT 5 Sebagai Upaya Peningkatan Keamanan Data Pada SMKK BPK Penabur Bandar Lampung, Studi Kasus : SMKK BPK Penabur Bandar Lampung.

[2] Darwis, Dedi.,Solehah, Nur Yulianti., 2016. Audit Tata Kelola Kemanan Informasi Pada Kantor Wilayah Kementerian Agama Provinsi Lampung Menggunakan Framework COBIT 5, Studi Kasus : Kantor Wilayah Kementerian Agama Provinsi Lampung.

[3] Anggoro A D., 2014. Analisis Kepatuhan Karyawan Terhadap KebijakanPengamanan Data pada PT XYZ dengan Standar COBIT 5, Program StudiTeknik Informatika Universitas Bakrie, Jakarta.

[4] ISACA 2012, Kerangka COBIT 5, COBIT 4.1, BMI

(ModelingBussinessInformation), Manajemen Tata Kelola, Jaminan Framework, Kerangka IT Risk, Major ISACA.

[5] Megawati, Fauzi,. 2014. Evaluasi Tingkat Kematangan Teknologi Informasi Dengan Menggunakan Model Maturity Level Cobit 4.1, Studi Kasus : PT. BRI Cabang Bangkinang.
[6] Raufan, Rani,. 2015. Audit Tata Kelola Teknologi Informasi Untuk mengontrol Manajemen Kualitas Menggunakan Cobit 4.1, Study Kasus : PT. Nikkatsu Electric Works.

[7] Romney, Steintbart ., 2015. Informasi Sistem Informasi, Jakarta.

[8] Syamsudin , emha,. 2014. Evaluasi Tingkat Kematangan Tata Kelola Teknologi Informasi STAIN Kediri Menggunakan Framework COBIT 5, Studi Kasus : Universitas Nusantara PGRI Kediri.

[9] Wardani S., 2014. Audit Tata Kelola Teknologi nformasi Menggunakan Framework COBIT dengan Model Maturity Level (Studi Kasus Fakultas ABC), Program Studi Teknik Informatika Universitas PGRI, Yogyakarta. 